\title{
In vivo IgA coating of anaerobic bacteria in human faeces
}

\author{
L A van der Waaij, P C Limburg, G Mesander, D van der Waaij
}

\begin{abstract}
The bacterial flora in the human colon, although extremely diverse, has a relatively stable composition and non-infectious anaerobic bacteria are dominant. The flora forms a pool of numerous different antigens separated from mucosal immunocompetent cells by just a single layer of epithelial cells. Despite this thin barrier, however, the colonic mucosa is physiologically only mildly inflamed. This study looked at the mucosal humoral immune response against faecal anaerobes. By flow cytometric analysis the in vivo immunoglobulin coating of anaerobic bacteria in faecal samples of 22 healthy human volunteers was determined. In a previous study flow cytometric analysis of faecal bacteria has been found to be a very sensitive method to detect immunoglobulins on faecal bacteria. This technique showed that in vivo many bacteria are coated with $\operatorname{IgA}(24-74 \%)$ and less with IgG and IgM. The presence of many bacteria coated with IgA implies that IgA coating does not result in permanent removal of the species from the colon. The absence of immunoglobulin coating suggests that there is immunological unresponsiveness for anaerobic bacterial antigens. It is concluded that both immunological unresponsiveness and preferential coating with $\operatorname{IgA}$ are responsible for the relative absence of colonic mucosal inflammation.

(Gut 1996; 38: 348-354)
\end{abstract}

Keywords: faeces, tolerance, immunoglobulins, anaerobic bacteria, mucosal immunology, flow cytometry. Departments of
Medical Microbiology and

L A van der Waaij

$\mathrm{D}$ van der Waaij

Internal Medicine

P C Limburg

G Mesander

University of

Groningen, the

Netherlands

Correspondence to:

Dr L A van der Waaij,

Department of Medical

Microbiology, University

Hospital Groningen

Hospital Groningen,

Oostersingel 59, $9713 \mathrm{EZ}$
Groningen, the Netherlands.

Accepted for publication

7 September 1995
Antigens, both of dietary and bacterial origin, are abundantly present in the colonic lumen. Bacterial antigens predominate as there are as many as $10^{11}$ bacteria per gram contents while most dietary antigens are degraded. It is important to realise that over $99.9 \%$ of the colonic microflora are part of a relatively stable ecosystem consisting of possibly as many as 400 different indigenous species as well as a few recently arrived species. Most of these anaerobic bacteria are not infectious and each these micro-organisms. ${ }^{1-3}$ Potentially pathogenic aerobic Enterobacteriaceae spp (like Escherichia coli) comprise less than $0 \cdot 1 \%$ of the colonic flora. To colonise and multiply within the mucus layer (mucus flora), bacteria must somehow anchor in the mucus layer or attach person has a characteristic combination of to the epithelial cells. From the mucus layer they may continuously seed into the colonic luminal contents where they continue to multiply and form the luminal (faecal) flora. In the colon the mucosal immune system consists of many lymphocytes, phagocytes, and predominantly IgA secreting plasma cells. These immunocompetent cells are separated from large amounts of different antigens present in the mucus layer and the colonic lumen by just a single layer of epithelial cells. The colonic mucosa is only mildly inflamed, however, despite continuous translocation of (bacterial) antigens through this epithelial barrier. ${ }^{4} \mathrm{~A}$ better understanding of the mechanisms that are responsible for the prevention of mucosal inflammation might give a clue for the pathogenesis of inflammatory bowel disease.

Two mechanisms may be important: (a) mucosal unresponsiveness to antigens of anaerobic bacteria - that is, absence of a mucosal immune response ${ }^{1-3}$ 5-8 and, (b) prevention of inflammation by the secretion of specific non-complement binding secretory $\operatorname{IgA}(\operatorname{sIgA}){ }^{9}$ Extremely little is known about the interaction between the anaerobic colonic flora and the mucosal immune system. ${ }^{10}$ This is due to both the difficulties associated with culturing anaerobic bacteria and the absence of sensitive methods to analyse this interaction. Recently we developed a flow cytometric method with which low levels of immunoglobulin (Ig) coating (hundreds of molecules) on anaerobic bacteria in faecal suspensions can be determined with great accuracy. ${ }^{11}$

In this study we analysed the in vivo immunoglobulin coating of faecal anaerobic bacteria in humans by flow cytometry. We show that many faecal anaerobic bacteria are coated with IgA, while others are coated with IgG, IgM or are not coated at all.

\section{Methods}

\section{Volunteers and sampling}

Twenty two healthy volunteers, 13 male and nine female, aged 21-61 years (median 32), provided a fresh faecal sample. Exclusion criteria were: immunocompromised conditions, IgA deficiency, antibiotic use less than two weeks before sampling, diarrhoea, and recent change in bowel habits. Each faecal sample was divided into portions of 0.5 gram, frozen within three hours after voiding, and stored until use at $-20^{\circ} \mathrm{C}$.

\section{Reagents}

Affinity purified polyclonal fluorescein 
isothiocyanate (FITC) labelled goat $F\left(a b^{\prime}\right)_{2}$ antihuman $\operatorname{IgA}, \operatorname{IgG}, \operatorname{IgM}(\mathrm{F} / \mathrm{P}$ ratios $2 \cdot 0$, Kallestad, Austin, TX), bovine serum albumin (BSA, fraction V, Boehringer Mannheim, Mannheim, Germany), and propidium iodide (PI, Sigma, St Louis, MO) were used.

\section{Study design}

Suspensions of faecal samples were analysed by flow cytometry. ${ }^{11}$ In vivo IgA, IgG, and IgM coating of anaerobic bacteria was determined by staining faecal suspensions with FITC$\mathrm{F}\left(\mathrm{ab}^{\prime}\right)_{2}$ antihuman IgA, IgG, of IgM and subtraction of background fluorescence as measured in unstained suspensions. ${ }^{12}$

\section{Flow cytometry}

Flow cytometry was performed as described in detail previously. ${ }^{11}$ Briefly, an EPICS-ELITE (Coulter-Electronics, Hialeah, FL) equipped with an Argon laser operating at $15 \mathrm{~mW}$ and $488 \mathrm{~nm}$ was used. Filter settings were $525 \mathrm{BP}$ for FITC, $550 \mathrm{LP}$ and $630 \mathrm{BP}$ for measurement of PI. Calibrations were done with Fluoresbrite plain microspheres (Polysciences, Warrington, PA) $0.72 \mu \mathrm{m}$ in diameter, on forward scatter (FSC), side scatter and FITC-fluorescence. Measurements were performed on 10000 events, at a flow rate of 1000-1500 events/s. The FITC-fluorescence was recorded logarithmically and fluorescence values were transformed into molecules of equivalent soluble fluorochrome (MESF). All events that stained with PI were regarded as bacteria and therefore, the discriminator was set on PI-fluorescence. An additional gate was set to exclude events with very large FSC (agglutinated bacteria). Analysis was done with standard ELITE software comprising the Immuno-4 program to determine the percentage of stained events by match region subtraction. ${ }^{12}$ The matched region ranged 10-80 units (of a total region of 1024) for the samples stained for IgA, IgG and some stained for IgM. For samples stained for IgM with very low and intermediate specific fluorescence, the matched region ranged 10-170 units. A second analysis was performed by simple threshold analysis. The threshold was set at $2100 \mathrm{MESF}$.

\section{Sample preparation}

Half a gram of faeces was suspended in $4.5 \mathrm{ml}$ bacteria free phosphate buffered saline (PBS), homogenised on a Vortex mixer, and centrifuged at low speed to separate larger faecal particles from bacteria. Samples containing about $10^{8}$ bacteria ( $20 \mu l$ supernatant) were washed once in $1 \mathrm{ml}$ of filtered PBS and centrifuged at $8000 \mathrm{~g}$ for 10 minutes to remove nonbound faecal-Ig. The pellet was resuspended in $60 \mu \mathrm{l}$ of BSA/PBS $(1 \%(w / v))$ as well as in FITC-labelled $\mathrm{F}(\mathrm{ab})_{2}$ anti-Hu IgA, IgG, or IgM $(1 \%$ in BSA/PBS $(1 \%$ (w/v)). After a 30 minute incubation period, suspensions were washed twice with PBS. Finally, the bacterial pellet was resuspended (Vortex) in $500 \mu \mathrm{l}$ PBS, mixed with $20 \mu \mathrm{l}$ PI (100 mg/l), stored on ice in the dark, and analysed within two hours.

\section{Mucus flocks}

All faecal samples were found to contain a number of small mucus flocks, which were densely packed with bacteria believed to represent the flora of the mucus layer (mucus flora). To analyse these flocks, three slides were prepared of each faecal suspension and sample preparation was essentially analogous to the procedure used for flow cytometry. ${ }^{1113}$ Briefly, half a gram of faeces of each sample was suspended in $4.5 \mathrm{ml}$ bacteria free PBS and homogenised on a Vortex mixer. The faecal suspensions were diluted to $2 \%$ in demineralised water with $0.5 \%$ TWEEN $80(\mathrm{v} / \mathrm{v})$ (Merck) and $10 \mu \mathrm{l}$ was pipetted into a well of three different degreased 12 well slides (Immunocor, France). After drying, fixation (acetone, 10 minutes), gentle washing in PBS and again drying, slides were stored $\left(-20^{\circ} \mathrm{C}\right)$ until use.

After thawing, one of each set of slides was stained with FITC-labelled goat $\mathrm{F}\left(\mathrm{ab}^{\prime}\right)_{2}$ antihuman IgA, washed gently three times for 10 seconds in PBS, embedded in mounting fluid (glycerol/TRIS buffer v/v 1:1), and stored in a moist chamber at $4^{\circ} \mathrm{C}$ in the dark. A second slide was not stained to analyse background fluorescence. The remaining slides were stained with the mucus stain alcian blue (routinely performed in the pathology department in the Academic Hospital of Groningen, Dr W Timens).

\section{Results}

In vivo coating with $\operatorname{Ig} A$

In a previous study, we have shown that immunofluorescence combined with flow cytometry is a very rapid and sensitive method to analyse Ig coating of uncultured anaerobic faecal bacteria. With this method, even a few hundred molecules of Ig per bacterium can be detected. ${ }^{11}$ Here we use this method to determine the in vivo IgA coating of anaerobic bacteria in faeces. Faecal suspensions of 22 human volunteers were incubated with FITC conjugated affinity purified polyclonal $\mathrm{F}\left(\mathrm{ab}^{\prime}\right)_{2}$ antihuman IgA. In Fig 1 we show examples of fluorescence histograms of both anti-IgA stained and unstained bacteria. As both histograms show considerable overlap, an advanced histogram subtraction method was used to determine the percentage of stained bacteria as well as their mean fluorescence. With match region subtraction, histograms of unstained samples are matched over a region with histograms of corresponding stained samples and subtracted (Fig 1). This subtraction method was found to be more accurate for analysis of overlapping distributions of stained and control samples, compared with simple subtraction or threshold analysis and nearly as good as curve fitting. ${ }^{11} 12$

In our samples analysed, a variable proportion of bacteria was coated with IgA (Fig 1). Of 

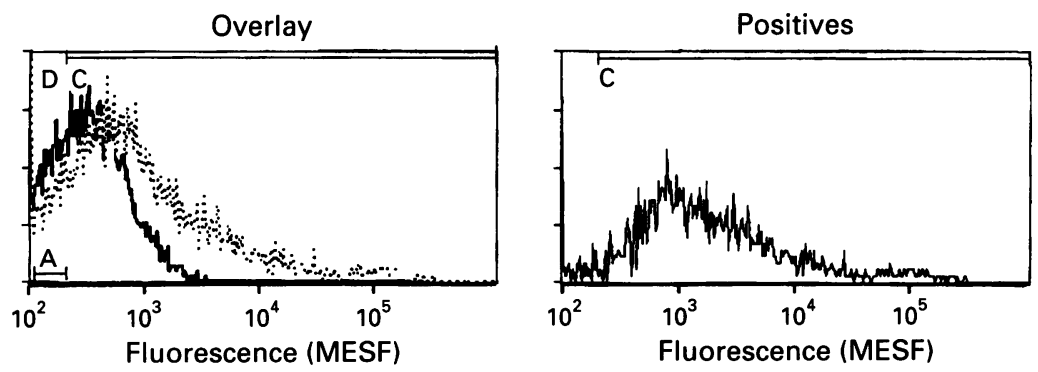

Figure 1: Histograms with typical FITC-fluorescence distributions of 10000 faecal bacteria stained with FITC-anti-Hu IgA (dotted line) or unstained (continuous line) as analysed by flow cytometry. To compute the percentage of bacteria coated with IgA, match region subtraction was performed (left histogram, immuno-4 software; refs 11, 12). The histogram of unstained bacteria is matched over a region (match region, $A$ ) with the corresponding histogram of stained bacteria, its height (size) adjusted, and thereafter both are subtracted. The resulting histogram shows the bacteria coated with IgA (right histogram). The percentage IgA coated bacteria is calculated over region C. FITC-fluorescence values are expressed in MESF. The sample of which the data are presented is identical to the sample used for Fig 3.
Because match region subtraction is an artificial method that can over as well as underestimate the real percentage of coated bacteria, we also performed conventional simple threshold analysis with the threshold set at a FITCfluorescence level at which only $0.2 \%$ of the unstained bacteria were positive $(2100$ MESF). By this method $13 \cdot 4 \%$ (4-30\%) of all bacteria were coated with IgA (Fig 2B).

The fluorescence distribution in most samples was characterised by a majority of bacteria with low and intermediate specific fluorescence intensities and only a tail of strongly fluorescent bacteria (Fig 1). The mean fluorescence intensity of the most strongly labelled bacteria (top $1 \%$ of all bacteria) present in each sample was $25 \times 10^{4}$ MESF. Although the size of bacteria could determine their IgA coating intensity, there was no clear correlation between bacterial size (FSC ${ }^{11}$ ) and their labelling with FITC antiIgA (Fig 3A). In fact, most of the strongly IgA coated bacteria had low FSC. In about half of the samples these bacteria formed a small $(<3 \%)$ distinct population in a FSC-fluorescence plot (Fig 4). mately 650 molecules of polyclonal FITC$\mathrm{F}\left(\mathrm{ab}^{\prime}\right)_{2}$ anti-IgA per bacterium $(\mathrm{F} / \mathrm{P}$ ratio $=2)$ and therefore less than 650 molecules of IgA.
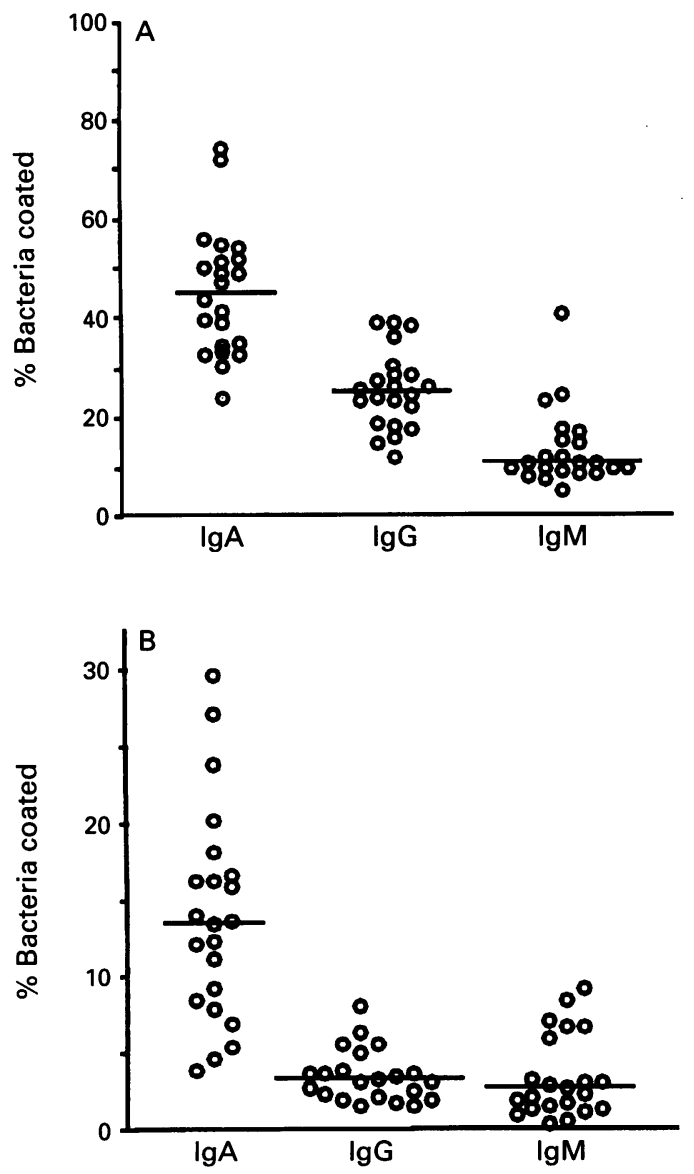

Figure 2: Flow cytometry analysis of faecal samples from 22 healthy human volunteers. Faecal anaerobic bacteria, isolated by centrifugation, were washed, stained with FITC-F(ab') ${ }_{2}$ anti-Hu IgA, IgG, or IgM, and 10000 events per staining were analysed. The percentages of faecal bacteria coated with IgA, IgG, or IgM present in each faecal sample are shown as determined by match region subtraction $(A)$ and by conventional threshold analysis (B). The threshold was set at a FITC-fluorescence larger than 2100 MESF - that is, larger than all unstained bacteria. The median percentage is shown by a line.

\section{In vivo coating with IgG or IgM}

The in vivo coating of faecal anaerobic bacteria with IgG and IgM was also determined by flow cytometry. Fig $2 \mathrm{~A}$ shows that the median percentage of bacteria labelled with FITC anti-IgG as analysed with match region subtraction was $25 \%$ (range 12-39). The labelled bacteria had a mean specific fluorescence of $700 \mathrm{MESF}$ (range 500-1100). With threshold analysis, 3.5\% (range $1 \cdot 5-8 \cdot 1$ ) of the bacteria were labelled (Fig 2B). The fluorescence distribution of most samples was characterised by comparatively low specific fluorescence intensities in the great majority of bacteria while strongly fluorescent bacteria were absent. There was no relation between bacterial size (FSC) and labelling with FITC anti-IgG (Fig 3B). In FSC-fluorescence plots, no distinct populations of strongly IgG coated bacteria were seen.

The median percentage of bacteria labelled with FITC anti-IgM was $11 \%$ (Fig $2 \mathrm{~A}$, range 5-41). Despite this lower percentage compared with IgG, the mean fluorescence intensities of IgM coated bacteria were higher: $1100 \mathrm{MESF}$ (range 600-2200). This was due to a much smaller population with low fluorescence intensities and a 'tail' of bacteria with higher fluorescence intensities. With threshold analysis, only $2.6 \%$ (range $0.4-9 \cdot 1$ ) of the bacteria were labelled (Fig 2B). There was no relation between bacterial size (FSC) and labelling with FITC anti-IgM (Fig 3C). In the FSC-fluorescence plot of only one sample, a distinct population of strongly IgM coated bacteria was seen. This population had similar FSC compared with the population of strongly IgA coated bacteria present in the same faecal sample.

\section{IgA coated bacteria in small faecal mucus flocks (mucus flora)}

The composition of the mucus flora as well as 

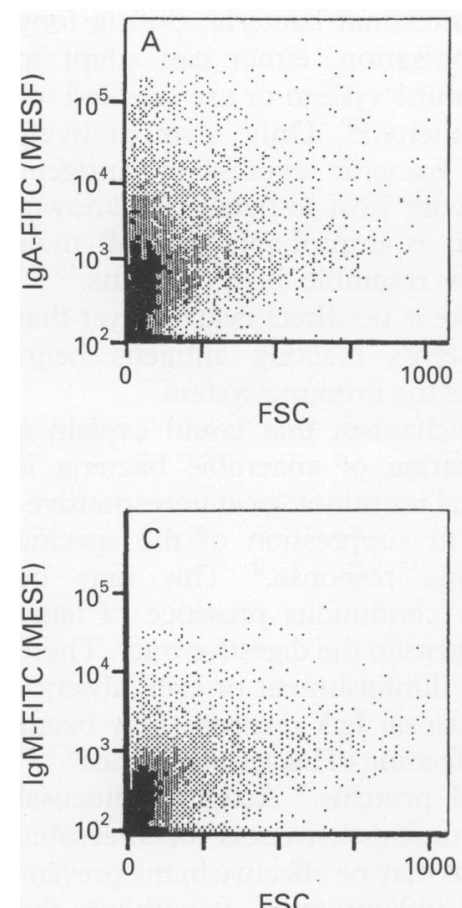

Figure 3: Typical relation between size (FSC) and FITC-fluorescence (MESF) of bacteria present in a faecal sample stained with FITC anti-Hu $\operatorname{Ig} A, \operatorname{Ig} G$ or $\operatorname{IgM}(A, B, C$, respectively) as determined by flow cytometry. Unstained bacteria are shown in (D). For each staining 10000 bacteria were analysed and each bacterium is represented by a dot.

the concentration of immunoglobulins within the mucus layer may be different from that of the lumen flora and lumen. Furthermore, the major interaction of bacteria with the mucosal immune system occurs within the mucus layer (mucus flora) covering the colon epithelium. By analysis of single faecal bacteria, however, only the luminal flora is investigated and this may introduce a bias. Therefore, small irregular flocks present in all faecal suspensions (and containing mucus flora) were analysed by phase contrast microscopy.

The flocks were found to consist of densely packed bacteria embedded in an amorphous substance (Fig 5). Most flocks had a diameter of about $15 \mu \mathrm{m}$, although some exceeded 300 $\mu \mathrm{m}$. Routine microscopic counting showed

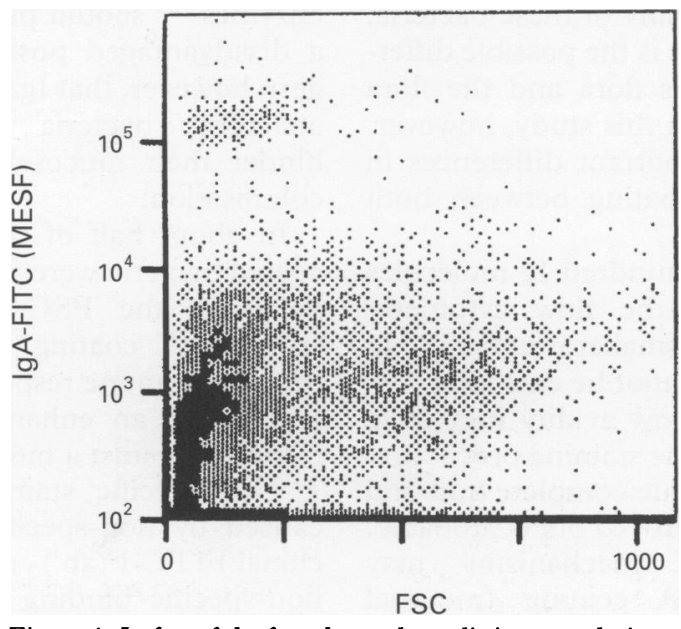

Figure 4: In few of the faecal samples a distinct population of strongly IgA coated bacteria was found in the FSC (bacterial size) versus FITC-fluorescence scatterplot. The FSC-FITC-fluorescence scatterplot of one of these samples stained with FITC anti-Hu IgA is shown. Fluorescence values are expressed in MESF. that the flocks were present in a concentration of about $10^{7}$ flocks/gram of faeces. All flocks stained with alcian blue showing that they contain intestinal mucus.

We wondered whether the bacterial population present within mucus flocks (mucus flora) is comparable to the population present as bacteria (and small agglutinates) scattered around the flocks (lumen flora). Therefore, we analysed both populations by phase contrast microscopy (Fig 5). The flocks contained a heterogeneous bacterial population that morphologically resembled the population present as separate bacteria. Furthermore, visual evaluation by fluorescence microscopy of samples stained with polyclonal FITC $\mathrm{F}\left(\mathrm{ab}^{\prime}\right)_{2}$ anti-Hu-IgA was performed. Because the eye, compared with flow cytometry, is not very sensitive for light, only strongly fluorescent bacteria could be detected. Flocks in all 22 samples contained bacteria with perceptible fluorescence, however, most bacteria had no visible fluorescence. The most strongly fluorescent bacteria within flocks had comparable morphology to those present as strongly fluorescent separate bacteria in the corresponding suspensions (Fig 5). This suggests that the bacterial population present in mucus flocks (mucus flora) is similar to the bacterial population present as separate bacteria in faecal suspensions (lumen flora). As dimeric sIgA may agglutinate bacteria, we have carefully analysed both flocks and lumen flora (separate bacteria and small agglutinates), for the presence of two or more strongly fluorescent bacteria agglutinated with each other (lying side by side). However, agglutination of strongly fluorescent bacteria was not seen (Fig 5).

\section{Discussion}

This study shows that about half of the (anaerobic) bacteria present in faecal suspensions of healthy human volunteers are coated with IgA (24-74\%), while considerably less bacteria are coated with IgG or IgM and others are not coated at all. Yet, the colonic mucosa is only mildly inflamed.

\section{Absence of IgA coating of a large portion of the} anaerobic colonic flora

Our findings clearly show that not all bacteria are in vivo coated with IgA despite an enormous amount of IgA present in the lumen. Faecal dry weight consists of $75 \%$ bacteria of which over $99.9 \%$ are anaerobic. Thus, the faecal flora comprises an enormous amount and variety of antigens. ${ }^{1-314}$ Anaerobic bacteria form a relatively stable ecosystem in a characteristic composition for each person, comprising presumably as many as 400 different predominantly non-pathogenic indigenous species. ${ }^{1-3}$ There is a continuous non-specific uptake of particulate (bacteria) and soluble antigens from the gut lumen by specialised epithelial cells ( $M$ cells), normal epithelial cells, and via tight junctions. ${ }^{415}$ It is therefore plausible, that antigens of all colonising anaerobic species are 


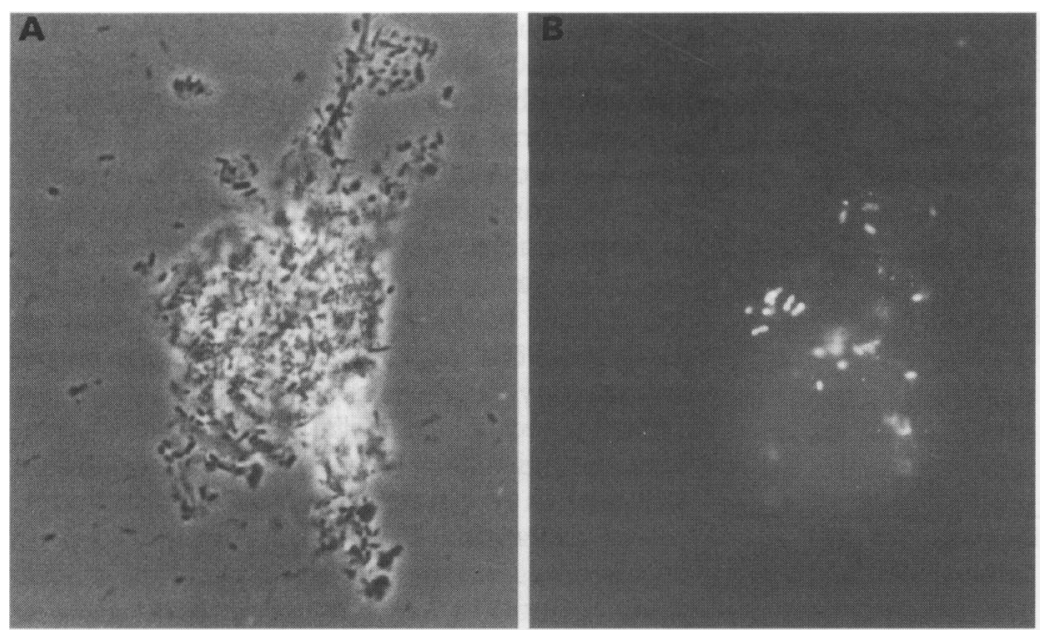

Figure 5: Phase contrast microscopic view of a faecal suspension shows a representative mucus flock that it is densely packed with bacteria $(2400 \times)$. Several separate bacteria are seen in the surroundings (left). The corresponding immunofluorescence picture after staining for IgA shows a few scattered strongly IgA coated bacteria (right).

continuously present within the mucosa and presented to the mucosal immune system. The most important effector system of the specific mucosal immune system is sIgA. Large amounts of sIgA ( $2.5 \mathrm{~g} /$ day), almost entirely produced by the mucosal immune system, are secreted into the lumen of the digestive tract. ${ }^{16}$ Rough estimates show that there are about $10^{7}$ sIgA molecules (specific as well as non-specific) available per faecal bacterium. Nevertheless, despite this enormous amount of $\operatorname{IgA}$, in vivo many bacteria are apparently not measurably coated with IgA.

Theoretically, the absence of IgA coating on many bacteria may be due to faecal proteases within the intestinal fluid, which may cleave Ig molecules into a Fc portion and a $F\left(a^{\prime}\right)_{2}$ fragment. However, faeces contain only very little proteolytic activity. ${ }^{17}$ Furthermore, our polyclonal FITC-anti-Hu IgA contains specificity for the $F\left(a b^{\prime}\right)_{2}$ portion of IgA and therefore FITC-labelling would not be influenced by this proteolytic activity. Indeed, a considerable number of bacteria were coated with IgA. Thus, faecal proteolytic cleavage of sIgA present on faecal bacteria also cannot explain the absence of IgA on many of these bacteria.

A second potential bias is the possible difference between the mucus flora and the flora analysed (faecal flora). In this study, however, we could not detect important differences in composition and IgA coating between both bacterial populations.

Although even a few hundred Ig molecules can be detected with the flow cytometry method, the presence of smaller numbers of Ig molecules on bacteria cannot be excluded. ${ }^{11} 12$ Furthermore, IgA with low avidity may have been washed off during the staining procedure. For all these reasons, a true complete humoral unresponsiveness is not proved but is probable.

Two immunological mechanisms may explain absence of IgA coating (mucosal immunological unresponsiveness) of faecal bacteria. Firstly, bacteria may use camouflage techniques by expression of host-identical epitopes on their surface antigens (intrinsic immunological unresponsiveness). It is plausible that intestinal bacteria, during long periods of colonisation, either can adapt to their host's immune system or are selected for non-immunogenicity. ${ }^{18}$ Only comparatively few intestinal bacteria expressing antigens cross reacting with host antigens are known, however, and it is improbable that all their surface antigens resemble host antigens. ${ }^{19-21}$ In addition, there is no direct evidence yet that expression of cross reacting antigens helps bacteria to evade the immune system.

A second mechanism that could explain a lack of $\operatorname{IgA}$ coating of anaerobic bacteria is acquired mucosal immunological unresponsiveness, resulting in suppression of the specific mucosal immune response. ${ }^{8}$ This may be induced by the continuous presence of large amounts of antigens in the digestive tract. There is evidence that diminishment or even absence of a specific mucosal IgA response may occur after prolonged feeding of bacterial antigens 6722 or non-bacterial proteins. ${ }^{5}$ Acquired mucosal immunological unresponsiveness for anaerobic bacterial antigens may be effective in the prevention of mucosal inflammation. It harbours the danger of derailment, however, with consequent loss of immunological unresponsiveness and thus a risk for mucosal inflammation. Such derailment could play a part in the pathogenesis of idiopathic inflammatory bowel disease.

\section{Many faecal anaerobic bacteria are coated with \\ $\operatorname{Ig} A$}

Despite the fact that presumably as many as $45 \%$ (match region subtraction), and at least $13 \%$ (conventional threshold analysis), of the bacteria are coated with IgA, the colonic anaerobic flora comprise a comparatively stable ecosystem of a heterogeneous bacterial population colonising the mucus. This is surprising because several antibacterial functions are attributed to IgA. For example synergism of IgA with non-specific antibacterial factors (for example, lactoferrin), immune exclusion (bacterial agglutination, prevention of epithelial attachment, and prevention of epithelial invasion), and inactivation of bacterial enzymes $^{9} 23$ should put IgA coated bacteria in a disadvantaged position. Our findings suggest, however, that IgA coating of these colonic anaerobic bacteria does not substantially hinder their mucosal adherence and mucus colonisation.

In about half of the samples strongly IgA coated bacteria were found as a separate population in the FSC-fluorescence plot. This strong IgA coating may represent either a primary immune response to a recently arrived species, or an enhanced secondary immune response against a more invasive species.

'Non-specific' staining of bacteria might be caused by non-specific binding of the polyclonal FITC-F $\left(\mathrm{ab}^{\prime}\right)_{2}$ anti-Hu IgA as well as by non-specific binding of the luminal secreted immunoglobulins. Non-specific binding of polyclonal FITC goat-F(ab') ${ }_{2}$ anti-Hu IgA with coated immunoglobulins or with bacterial surface antigens has been previously studied and does not occur. ${ }^{11}$ Non-specific binding of 
the luminal secreted immunoglobulins to bacteria may be present as several aerobic bacterial species contain $B$ cell superantigens. B cell superantigens, for example, staphylococcal protein $\mathrm{A}$, are bacterial antigens that non-specifically bind to a large proportion of IgA, IgG, or IgM. ${ }^{24}$ However, it is not known whether anaerobic species carry B cell superantigens. Furthermore, non-specific binding of immunoglobulins may have the same effects on bacteria as specific binding.

Agglutination of bacteria is believed to be an important mechanism by which dimeric sIgA prevents bacteria entering the mucosa. ${ }^{9}$ In this study, however, agglutination of strongly IgA coated (anaerobic) bacteria was not seen in either mucus flocks, where IgA concentrations may be high and influence of peristalsis is low, or in faecal suspensions. This suggests that the resident anaerobic bacteria must have developed, as yet unknown, strategies to evade agglutination.

In conclusion, sIgA may play a different part for indigenous anaerobes than for transient organisms that may be pathogens. IgA coating may stabilise the colonic flora and contribute to the colonisation resistance. ${ }^{25}$

\section{In vivo coating with IgG and IgM}

In this study we show that on average $25 \%$ of all bacteria present in faecal suspensions are coated with $\operatorname{IgG}$, whereas about $11 \%$ are coated with IgM. The presence of IgG and IgM coated bacteria is plausible as the colon harbours $10^{10}$ plasma cells per metre of which $4 \%$ secrete IgG and $6 \%$ IgM, besides the predominant IgA secreting plasma cells $(90 \%){ }^{26}$

In contrast with intestinal IgA and IgM, which are almost exclusively produced within the mucosa, intestinal IgG is presumably derived from serum as well. ${ }^{26}$ The function of mucosal (intestinal) IgG is not known, although blocking of bacterial adherence to epithelial cells has been described. ${ }^{27}$ As IgG is a monomer and, in contrast with secretory IgA, susceptible to proteolytic activity, it may be less effective in opsonisation and agglutination of bacteria in the intestinal lumen. ${ }^{28}$ Therefore, its function may lay merely within the mucosal tissue. The coating of anaerobic bacteria with IgG in the intestinal lumen may have no influence on their colonisation and may be partly the result of a leakage of IgG into the lumen.

$\operatorname{IgM}$ is usually polyreactive with specificity for carbohydrate antigens, which are often expressed on bacterial surfaces. Therefore, sIgM may be important in the first line of defence against invading bacteria. Despite the polyreactive nature of $\operatorname{IgM}$, however, only a small percentage of faecal anaerobic bacteria was coated with IgM. This suggests either that these polyreactive $\operatorname{IgM}$ molecules have low avidity and have been washed off during the staining procedure, or absence of mucosal polyreactive $\operatorname{IgM}$ with specificity for the anaerobic bacteria. This last explanation could result from acquired mucosal immunological unresponsiveness.
We conclude that a comparatively large proportion of anaerobic faecal bacteria are not in vivo coated with IgA and a somewhat smaller proportion are not coated with Ig at all. This may be largely due to acquired mucosal immunological unresponsiveness. A substantial proportion of anaerobic faecal bacteria, however, are coated with IgA and less with IgG or IgM. As the colonic flora have nevertheless a stable composition and the colonic mucosa is normally only mildly inflamed, this Ig coating cannot be harmful, either to these bacteria or to their host. It is important to realise that most anaerobic bacteria are beneficial to the host ${ }^{29}$ and therefore, killing or rejection of commensal bacteria may not be the goal of the mucosal immune system. ${ }^{9}$ Both immunological unresponsiveness for certain colonising bacteria and coating with IgA of others may prevent clinical colonic inflammation when they or their antigens penetrate the epithelial lining.

The authors would like to thank N K van der Waaij-de Boer and Dr F G M Kroese for critically reading the manuscript, Professor Dr W Timens for staining faecal suspensions with alcian blue.

This work was supported by V C Rusch, Dr rer nat Institute for Microbiology and Biochemistry, Herborn-Dill, Germany.

1 Gossling J, Slack JM. Predominant gram-positive bacteria in human feces: numbers, variety, and persistence. Infect Immun 1974; 9: 719-29.

2 Moore WEC, Holdeman LV. Human fecal flora: the normal flora of 20 Japanese-Hawaiians. Appl Microbiol 1974; 27: 961-79.

3 Simon GL, Gorbach SL. Intestinal flora in health and disease. Gastroenterology 1984; 86: 174-93.

4 Wells CL, Maddaus MA, Simmons RL. Proposed mechanisms for the translocation of intestinal bacteria. Rev Infect Dis 1988; 10: 958-79.

5 Elson CO. Induction and control of the gastrointestinal immune system. Scand $\mathcal{f}$ Gastroenterol 1985; 20 (suppl 114): 1-15.

6 Hahn-Zoric M, Carlsson B, Jalil F, Mellander L, Germanier $\mathrm{R}$, Hanson LA. The influence on the secretory IgA antibody levels in lactating women of oral typhoid and parenteral cholera vaccines given alone or in combination. Scand F Infect Dis 1989; 21: 421-6.

7 Riviere GR, Wagoner MA, Freeman IL. Chronic peroral immunisation of conventional laboratory rats with mutans immunisation of conventional laboratory rats with mutans streptococci leads to stable acquired suppression of sa

8 Waaij D van der, Heidt PJ. Development of immunological tolerance to the mucosa-associated flora: a possible prerequisite for mitigation of graft-vs-host disease in bone-marrow transplant recipients. In: Jeljaszewicz J, Pulverer G, eds. Antimicrobial agents and immunity. London: Academic Press, 1986: 189-216.

9 Childers NK, Bruce MG, McGhee JR. Molecular mechanisms of immunoglobulin A defense. Annu Rev Microbiol 1989; 43: 503-36.

10 Monteiro E, Fossey J, Shiner M. Antibacterial antibodies in rectal and colonic mucosa in ulcerative colitis. Lancet 1971; i: 249-51.

11 Waaij LA van der, Mesander G, Limburg PC, Waaij D van der. Direct flow cytometry of anaerobic bacteria in human der. Direct flow cytometry of anaeroby

12 Sladek TL, Jacobberger JW. Flow cytometric titration of retroviral expression vectors: comparison of methods for analysis of immunofluorescence histograms derived from cells expressing low antigen levels. Cytometry 1993; 14: 23-31.

13 Apperloo-Renkema HZ, Wilkinson MHF, van der Waaij D. Circulating antibodies against fecal bacteria assessed by immunomorphometry: combining quantitative immunofluorescence and image analysis. Epidemiol Infect 1992; 109: 497-506.

14 Stephen A, Cummings CJH. The microbial contribution to human fecal mass. I Med Microbiol 1980; 13: 45-56.

15 Owen RL, Pierce NF, Apple RT, Cray WC. M cell transport of Vibrio cholerae from the intestinal lumen into port of Vibrio cholerae from the intestinal lumen into microbial transepithelial migration. F Infect Dis 1986; 153: microbial

16 Conley ME, Delacroix DL. Intravascular and mucosal immunoglobulin A: two separate but related systems of immune defense? Ann Intern Med 1987; 106: 892-9.

17 Vos T de, Dick TA. A rapid method to determine the isotype and specificity of coproantibodies in mice infected with Trichinella or fed cholera toxin. F Immunol Methods 1991; 141: 285-8. 
18 Duval-Iflah Y, Raibaud P, Rousseau M. Antagonisms among isogenic strains of Escherichia coli in the digestive

19 Ferretti JJ, Shea C, Humphrey MW. Cross-reactivity of streptococcus mutans antigens and human heart tissue. Infect Immun 1980; 30: 69-73.

20 Foo MC, Lee A. Antigenic cross-reaction between mouse intestine and a member of the autochthonous microflora. Infect Immun 1974; 9: 1066-9.

21 Yu DTY, Hamachi T, Hamachi M, Tribbick G. Analysis of the molecular mimicry between HLA-B27 and a bacterial OmpA protein using synthetic peptides. Clin Exp Immunol 1991; 85: 510-4.

22 Logan AC, Chow KPN, George A, Weinstein PD, Cebra JJ Use of Peyer's patch and lymph node fragment cultures to compare local immune responses to Morganella morganii. Infect Immun 1991; 59: 1024-31.

23 Williams RC, Gibbons RJ. Inhibition of bacterial adherence by secretory immunoglobulin A: a mechanism of antigen

24 Silverman GJ. Human antibody responses to bacterial antigens: studies of a model conventional antigen and a proposed model B cell superantigen. Intern Rev Immunol 1992; 9: $57-78$.

25 Waaij D van der, Berghuis-de Vries JM, Lekkerkerk-van der Wees JEC. Colonisation resistance of the digestive tract in conventional and antibiotic-treated mice. F Hyg 1971; 69: 405-11.

26 Brandtzaeg P, Valnes K, Scott H, Rognum TO, Bjerke K, Baklien $\mathrm{K}$. The human gastrointestinal secretory immune system in health and disease. Scand $\mathcal{F}$ Gastroenterol 1985; 20 (suppl 114): 17-38.

27 Svanborg-Eden C, Svennerholm AM. Secretory immunoglobulin $A$ and $G$ antibodies prevent adhesion of Escherichia coli to human urinary tract epithelial cells. Infect Immun 1978; 22: 790-7.

28 Brandtzaeg P, Bjerke K, Kett K, Kvale D, Rognum TO, Scott $\mathrm{H}$, et al. Production and secretion of immunoglobulins in the gastrointestinal tract. Ann Allergy 1987; 59: 21-39.

29 Waaij $D$ van der. The ecology of the human intestine and its consequences for overgrowth by pathogens such as Clostridium difficile. Annu Rev Microbiol 1989; 43: 69-87. 